This item was submitted to Loughborough's Research Repository by the author.

Items in Figshare are protected by copyright, with all rights reserved, unless otherwise indicated.

\title{
The sedentary office: an expert statement on the growing case for change towards better health and productivity
}

\section{PLEASE CITE THE PUBLISHED VERSION}

http://dx.doi.org/10.1136/bjsports-2015-094618

\section{PUBLISHER}

C BMJ Publishing Group Ltd and the British Association of Sport and Exercise Medicine

\section{VERSION}

AM (Accepted Manuscript)

\section{PUBLISHER STATEMENT}

This work is made available according to the conditions of the Creative Commons Attribution-NonCommercialNoDerivatives 4.0 International (CC BY-NC-ND 4.0) licence. Full details of this licence are available at: https://creativecommons.org/licenses/by-nc-nd/4.0/

\section{LICENCE}

CC BY-NC-ND 4.0

\section{REPOSITORY RECORD}

Buckley, John P., Alan Hedge, Thomas E. Yates, Robert J. Copeland, Michael Loosemore, Mark Hamer, Gavin Bradley, and David W. Dunstan. 2019. "The Sedentary Office: An Expert Statement on the Growing Case for Change Towards Better Health and Productivity”. figshare. https://hdl.handle.net/2134/19154. 
Public Health

England

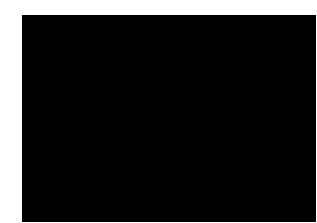

\title{
The sedentary office: a growing case for change towards better health and productivity
}

\author{
Expert statement commissioned by Public Health England and Active \\ Working C.I.C.
}

Buckley JP, Hedge A, Yates T, Copeland R, Loosemore M, Hamer M, Bradley G, Dunstan DW.

\section{Background and general aims}

The overall aim of this expert statement is to provide guidance for employers and staff working in office environments to combat the potential ills of long bouts of seated office work. In the past five years, an accelerated amount of evidence has been published on the links between sedentary living, including time at work, and the leading causes of morbidity and mortality (cardiovascular disease, diabetes and some cancers). Much of the evidence has been from crosssectional and/or prospective observational studies, however, a number of more recent intervention studies have highlighted potential mechanisms in an attempt to demonstrate causality. These outcomes have captured much journalistic attention from news and documentaries on television, weekly articles in newspapers and features within the popular press on science, ergonomics and health. An expert panel has therefore drawn up some preliminary core recommendations (Box 1.) as an initial guide for employers, ergonomists, office furniture and equipment suppliers and occupational health promoters. 
Box 1.

\section{Core recommendations}

For those occupations, which are predominantly desk-based, workers should aim to follow these recommendations:

- *Initially progress towards accumulating at least two-hours per day of standing and light activity (light walking), eventually progressing to a total accumulation of four hours per day (pro-rated to part-time hours)

- Seated-based work should be regularly broken up with standing-based work and vice versa and thus sit-stand adjustable desk stations are highly recommended.

- Similar to the risks of prolonged static seated positions, so too should prolonged static standing postures be avoided; movement does need to be checked and corrected on a regular basis especially in the presence of any musculoskeletal sensations ${ }^{1}$. Occupational standing and walking have however not shown to be causally linked to low back and neck pain and can provide relief 23

- Those individuals new to adopting more standing-based work could expect some musculoskeletal sensations and some fatigue as part of the positive adaptive process. If such sensations cannot be relieved either by an altered posture or walking for a few minutes, then the worker should rest, including sitting, with a posture that relieves the sensations. If discomfort does persist, then seeking appropriate medical advice is recommended.

- Along with other health promotion goals (improved nutrition, reducing alcohol, smoking and stress), companies should also promote to their staff that prolonged sitting, aggregated from work and leisure-time, may significantly increase one's risk of cardio-metabolic diseases and premature mortality.

*Whilst more evidence is required to add greater certainty to this set of recommendations, or evolve and/or change them, the key elements remain to highlight the potential ills of sitting for prolonged periods and emerging benefits of changing office environments that promote standing and movement. Employers need to evaluate the best ways to achieve this, whether it be changes to how and when people can take breaks which involve standing and movement or desk designs and technologies that allow people to perform their work more easily either at their desk location or from other locations within the office space in a standing-up position. On the basis that there are a large number of occupations which involve people standing and moving for considerably more than four hours per day (e.g. hospital staff, teachers, factory workers, retail and catering staff), it is expected that for office-based workers in general this should not pose too many significant physical or cognitive challenges. 

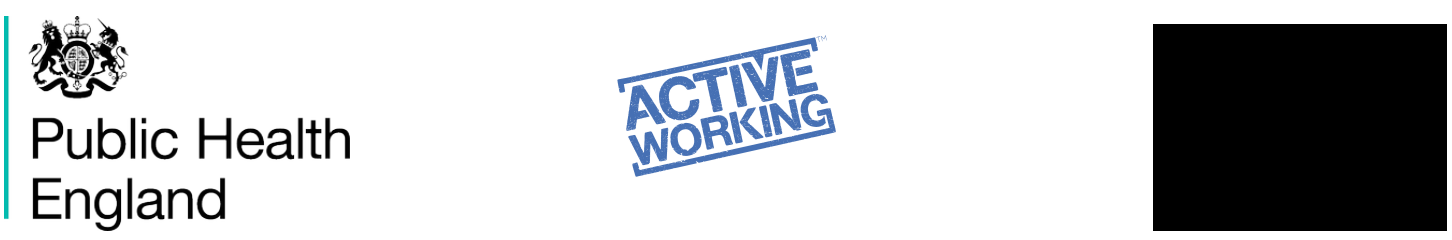

The growing interest in changing sedentary working environments has led to a proportionate acceleration in the production, marketing and sales of commercial and domestic furniture retailers with either sit-stand attachments for desks or fully adjustable sit-stand desk-tops. Marketing claims for such products have focused on the additional energy expenditure, with alleged benefits to weight control/loss, relief and prevention of musculoskeletal conditions (acute and chronic), and improved cardio-metabolic health. Although these products do come with some guidance on their use, there is a paucity of guidance relating to affecting a number of factors that may best help realise the promoted health benefits, including: long-term behaviour change processes and daily doses (sustained versus fractions of time) of standing and active breaks required at work within the office environment.

This expert statement therefore aims to provide some primary guidance (highlighted below) to support, as best as possible, those employers and staff who have invested or plan to invest in creating less sedentary and more active working environments. Market trends, which are adding momentum to such investments, may however be moving at a faster pace than the related and supporting evidence-base can be produced. The notion of an intervention which can improve employee well-being and performance has concomitantly attracted interest from arenas of occupational health and human resources. This guidance thus represents a summary and extrapolation of the evidence to date. Future refinements will be required as more evidence is published.

\section{Rationale, evidence and objectives}

In meeting the above aims, the two objectives of this expert statement are to highlight: $i$. the effects of prolonged seated desk-work on the health and wellbeing of office-based workers and ii. how a less sedentary office environment potentially influences productivity, both intrinsically for the individual worker and extrinsically for the corporate achievements of an organization, including economic savings and benefits from improved productivity, profitability, and reduced sickness and absenteeism. Overall, social-political theorists have captured these values under the term "Corporate Social Responsibility" (CSR) 4 . Historic examples of CSR date back to Victorian times (the 1870s), which includes examples such as the Cadbury chocolate company, who provided facilities and a living community designed for promoting a physically and socially healthy working, living and leisure environment for workers and their families.

Within the context of this current expert statement, sedentary behavior is defined in its truest sense (from its Latin roots "sedere") as meaning time spent sitting ${ }^{5}$. The simple act of postural changes, standing and movement/ambulation within an office space is considered to be light intensity activity ${ }^{6}$, which can add 0.5 to 2.0 kcals per minute of energy expenditure compared to sitting still whilst performing computer work ${ }^{7-9}$. Although this added energy expenditure may intuitively be translated to potential weight-loss, the current evidence is equivocal on whether increased standing at work could 

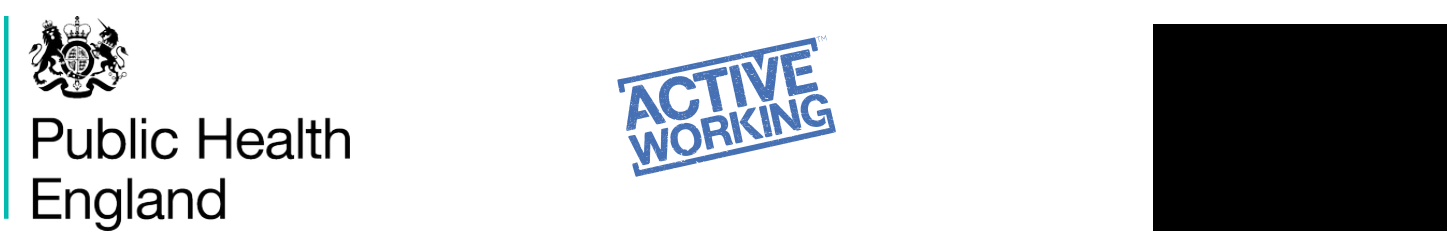

have a significant impact on reducing obesity. Nevertheless, analyses by magnetic resonance imaging (MRI) do show, is that fat deposited around vital organs (heart, kidneys and liver) are much more strongly associated with objectively measured sedentary time compared to overall body mass index ${ }^{1011}$. The most encouraging evidence thus far demonstrates that avoiding long bouts of sitting coupled with even short but frequent bouts of more light intensity movement improves glucose and insulin levels ${ }^{812-14}$. Such strategies have also been shown to reduce musculoskeletal (e.g. low back) discomfort and fatigue in office workers ${ }^{15}$.

\section{Sedentary behavior within the context of human physical activity}

In the lead-up to the London 2012 Olympic and Paralympic Games, a special edition of the Lancet published a series of papers, based on national statistics from around the world, that globally $\sim 40 \%$ of individuals with cardiovascular disease, diabetes or cancer failed to achieve the minimum recommendations for health of 150 minutes per week of moderate intensity physical activity ${ }^{16}$. In high-income countries in Europe and North America this figure rose to $\sim 70 \%$. More worryingly, if objective measures of physical activity are used, 95\% of adults in the general population are classified as inactive ${ }^{17} 18$. As part of the World Health Organisation's (WHO) $25 \times 25$ initiative (reducing premature mortality by $25 \%$ from non-communicable diseases by the year 2025), a specific target has been set to decrease physical inactivity by $10 \%$. In the UK this has been translated into a year on year decrease in the number of people performing less than 30 mins of activity per week ${ }^{19}$.

Reducing physical inactivity is as much about reducing sedentary time as it is about getting people to attain a weekly target energy expenditure of $1000+\mathrm{kcals}$ (e.g. 150 minutes of moderate intensity activity per week) ${ }^{5}$. It is as much (if not more) about reducing sedentary time spent at work, home and in leisure. In the UK, sedentary behavior now occupies around $60 \%$ of people's total waking hours in the general population and over $70 \%$ in those with a high risk of chronic disease 2021 . For those working in offices, 65 to $75 \%$ of their working hours are spent sitting, of which more than $50 \%$ of this is accumulated in prolonged bouts of sustained sitting; on non-working days people sit less by up to 2.5 hours ${ }^{22-27}$. The evidence is clearly emerging that a first "behavioural" step could be to simply get people standing and moving more frequently as part of their working day (Figure 1). Moreover, in the workplace this may potentially be more socially achievable that targeted exercise. The UK's 2011 Chief Medical Officers' report confirms such an approach, and it provides a clear graphic (Figure 2.) where the steepest component of the risk reduction curve occurs in taking people from a sedentary state to one of at least standing or light intensity activity 5 .

Over the past five decades, the culprits of sedentary behavior in both developed and developing nations have included: reduced frequent bouts of active human transport (walking, cycling), increased sedentary leisure pursuits at home 

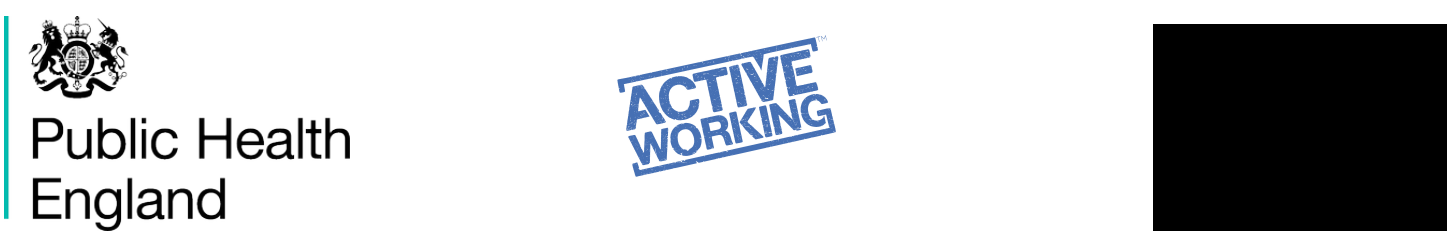

(television viewing and computer-based activities) and less manual occupations with increased amounts of seated technical work or desk-based office work ${ }^{28}$. Since 1960 the estimated energy expenditure loss at work has been 175 kcals per day ${ }^{29}$ coinciding with a $20 \%$ reduction in physical activity, which on current trends could be $35 \%$ by $2030^{30}$. Coupled within these figures is a reduction of walking in the UK by 60 miles per year since $1975^{31}$, where the minimum total loss of energy expenditure in daily life for the average working person is $\sim 200$ kcals per day. Most of this reduced energy expenditure has therefore been in the form of light physical activity and not necessarily from decreased active leisure, exercise or sporting pursuits which has traditionally been the sole focus of many health, social and political campaigns 52032 . In lower socioeconomic groups and ethnic minorities there has also been a decline in both light daily movements and active leisure and sport ${ }^{33}$.

In observational research, daily hours spent being sedentary (sitting), independent of levels of exercise or physical activity, are positively correlated with the risk of diabetes, cardiovascular disease, some cancers and premature mortality ${ }^{34-37}$. For example a comprehensive review of the data found that compared to those who sit the least, those who sit the most have over twice the risk of developing type 2 diabetes and cardiovascular disease ${ }^{38}$. Similarly, it has been found that every additional hour of TV viewing per day is linked to a $10 \%$ higher risk of developing type- 2 diabetes and a 7.5\% higher risk of developing cardiovascular disease 38 39. These associations may, however, be attenuated in people that undertake regular moderate-to-vigorous physical activity ${ }^{40}$. Furthermore, those who spend more time sitting at work also spend more time sitting during leisure time ${ }^{23}$. A number of studies in relation to television viewing have shown adverse associations with mental health and wellbeing ${ }^{41-43}$ and muscle strength ${ }^{44} 45$. Current evidence on overall risk of premature mortality from sedentary behavior suggests that for those sitting more than seven of hours per day, there is a 5\% increased risk with each additional hour of sitting ${ }^{46}$. Overall this demonstrates that strategies to incorporate reduced sitting within working hours could offer significant risk reduction

\section{Sedentary office environments}

Policies for addressing concerns around inactive working environments have been well documented within national service frameworks for public health and medicine ${ }^{19}{ }^{47}$. As previously noted, declines in energy expenditure at work over the past five decades have increasingly been the result of large proportions of the population moving from jobs in a standing or light activity mode to those at a seated work-station. Morris et al. ${ }^{48}{ }^{49}$ were the very first to scientifically demonstrate the link between physical inactivity and morbidity or premature mortality in sedentary occupations (bus drivers and office-based postal workers). Results were presented as a "relative risk" between active and sedentary occupations, and the rates of morbidity and mortality could either be equally or 

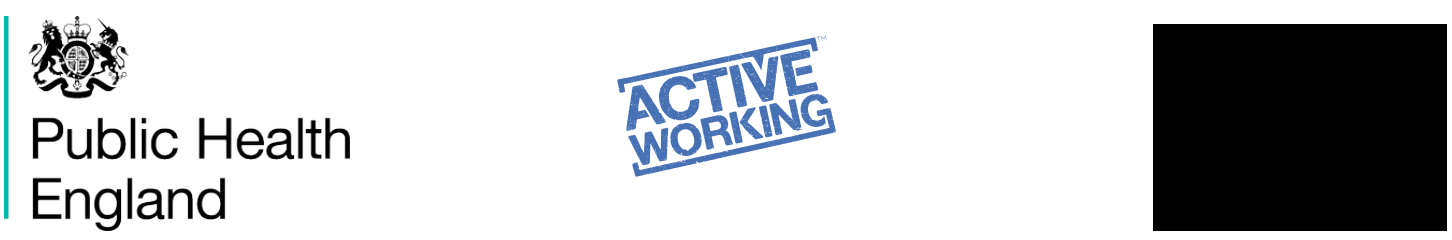

at least partially associated with sedentary work and not simply with the active occupations. In also considering that developed countries will also be facing an aging workforce, where the age of retirement is set to rise ${ }^{50}$, excessive sitting in the office environment could increase chronic exposure to sedentary behaviour through the lifecourse, with consequences for unhealthy ageing ${ }^{51}$ and poorer bone health in later life ${ }^{52}$.

Standing time at work has more recently demonstrated a dose-response type relationship, based on longer-term epidemiological data ( $>10$ years), with cardio metabolic, musculoskeletal, mental health risks and overall mortality (Katzmarzyk, 2014, Dempsey et al., 2014). In this same period a coinciding proliferation of sit-stand workstations has been widely marketed in Europe and North America. Data from the Furniture Industry Research Association (FIRA) estimate that $90 \%$ of office workers in Scandinavia now have access to sit-stand workstations, but in the UK the figure is only 1\%. Whilst the impact on health outcomes are yet to be demonstrated from such widespread initiatives in Scandinavia, it provides a welcome opportunity for health scientists to evaluate the reality of the intuitive/perceived benefits being promoted by both the furniture industry and employers wanting to engage in new approaches to improving wellbeing and performance.

In the event that the evidence continues to demonstrate the health risks of prolonged seated work, then a strong case for changing the ergonomic design of offices and work stations along with movement behaviours during the working day should be supported 327 53-55. There are, however, strong indications that simply changing the office environment might not be enough to invoke long-term change in behaviour. Strategies and programmes for implementing change will need careful organisational and behavioural support and public education to prevent current interests in active office environments from simply being a passing fad 535657 .

From the observational and experimental evidence cited thus far, the amount of time office workers should avoid sitting equates to a minimum accumulation of standing and/or moving within the office space for at least two hours per day but ideally four hours per day. On this basis the core recommendations are made (Box 1.).

Future evidence requires longer-term prospective and randomized controlled trials assessing standing and light activity interventions in real office environments, and their effect on long-term health outcomes. These studies should include assessing the impact of creating "movement friendly" spaces for both purposeful and non-purposeful movement ${ }^{58}$, including: computer-based prompts, alarmed or vibrating personal motion assessment devices, placement of toilets, kitchens, meeting places on different floors, stair-use promotions, standing meetings and messages delivered in person verbally or by hand. Much of the current evidence is based on epidemiological data, with proposed 

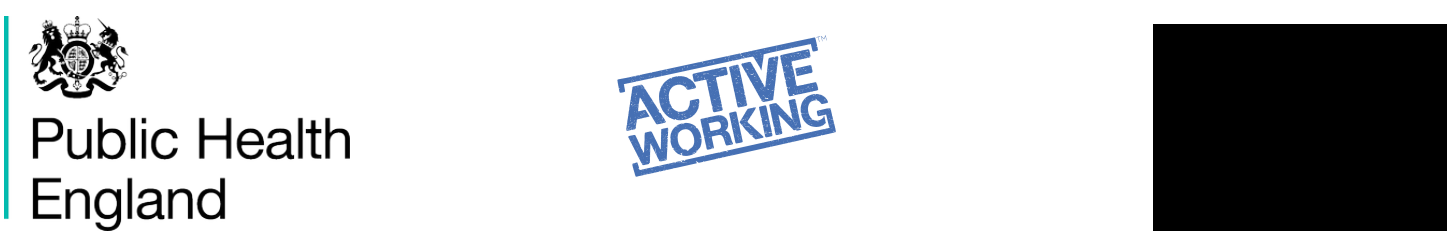

mechanisms measured from shorter-term bouts of standing or light activity often performed within highly controlled settings. Behavioural perceptions and long-term adherence to standing-based office work, or work which includes regular bouts of standing and/or light activity around the office, requires greater attention.

\section{The financial case for change}

There are a several potential financial reasons for reducing the average daily sitting time in the population below 9.0 hours ( $\sim 60 \%$ of waking hours; 6 to 7 hours at work and 3 hours at home), including: reduced healthcare costs, and cost-savings-benefits from improved workforce productivity, engagement and reduced absenteeism.

The significant healthcare costs to the nation in relation to physical inactivity and sedentary behavior have been widely reported, especially in relation to cardiovascular disease, cancer and the increasing incidence and prevalence of diabetes and obesity 5203259 . The most recent figures from the UK's Office for National Statistics (2014) highlight that of the 131 million working days lost to sickness, the largest contributing factor ( $\sim 25 \%$; 31 million days) is back, neck and muscle pain. Stress, anxiety and depression are also large contributors ( 12\%; 15 million days). Manual occupations have the largest proportion of total hours of sickness $(2.4-3.2 \%)$ but the next highest are office-based administrative/secretarial/sales or customer service occupations (2.1 - 2.2\%). The rate of sickness-absences is influenced strongly by such factors as the size of the organization (negative correlate) and the level of professional skill or qualifications and pay (positive correlation).

Key studies from Australia have demonstrated a potential ameliorating influence of workplace interventions, which promote standing breaks and or the ongoing use of sit-stand adjustable work-stations. Not only did these interventions lead to improvements in markers of health risk but also improved work productivity, quality, efficiency and greater senses of collaboration amongst groups of employees 155460 . Furthermore these studies revealed that "healthy workers rate their work performance greater than less healthy workers; those or who are experiencing injury or illness are more likely to be absent from work and reduced sedentary practices can reduce the risk of musculoskeletal disorders". All of these examples provide cost savings to both the health service and the employer, along with any knock-on costs to illness or injury that affects the productive lives of significant others (e.g. one's family or close friends needing time to assist or care).

\section{Acknowledgements}

The authors are grateful to the expert "sounding-board" advice of: Justin Varney, Michael Brannan, Stuart Biddle and Nanette Mutrie, Philipa Dall, Sebastien Chatin. 

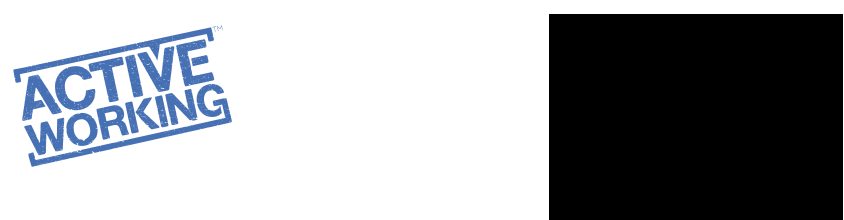

Public Health England and Active Working C.I.C. are grateful for the support from their stakeholders:

\section{Confirmed Stakeholder Supporters:}

Macmillan, Men's Health Forum, Obesity Society, BackCare. Corporate Health, Leicester Diabetes Centre, NIHR Leicester-Loughborough Biomedical Research Unit, UKactive, Investors in People,

\section{References}

1. Pope MH, Goh KL, Magnusson ML. Spine ergonomics. Annual review of biomedical engineering 2002;4:49-68.

2. Roffey DM, Wai EK, Bishop P, et al. Causal assessment of occupational standing or walking and low back pain: results of a systematic review. The spine journal : official journal of the North American Spine Society 2010;10(3):262-72.

3. Pronk NP, Katz AS, Lowry M, et al. Reducing occupational sitting time and improving worker health: the Take-a-Stand Project, 2011. Preventing chronic disease 2012;9:E154.

4. Katsoulakos P, Koutsodimou, M., Martrag, A., Williams, L. A hisotric perspective of the CSR movement; a CSR oriented business management framework, part A-CSR foundations. Athens University of Economics,, 2004.

5. CMOs. Start Active Stay Active, a report of the UK's Chief Medical Officers. London, 2011.

6. Chastin SF, Granat MH. Methods for objective measure, quantification and analysis of sedentary behaviour and inactivity. Gait \& posture 2010;31(1):82-6.

7. Levine JA. Non-exercise activity thermogenesis (NEAT). Nutrition reviews 2004;62(7 Pt 2):S82-97.

8. Buckley JP, Mellor DD, Morris M, et al. Standing-based office work shows encouraging signs of attenuating post-prandial glycaemic excursion. Occupational and environmental medicine 2014;71(2):109-11.

9. Ainsworth BE, Haskell WL, Herrmann SD, et al. 2011 Compendium of Physical Activities: a second update of codes and MET values. Medicine and science in sports and exercise 2011;43(8):1575-81.

10. Smith L, Thomas EL, Bell JD, et al. The association between objectively measured sitting and standing with body composition: a pilot study using MRI. BMJ open 2014;4(6):e005476.

11. Henson J, Edwardson CL, Morgan B, et al. Associations of Sedentary Time with Fat Distribution in a High-Risk Population. Medicine and science in sports and exercise 2014.

12. Dempsey PC, Owen N, Biddle SJ, et al. Managing sedentary behavior to reduce the risk of diabetes and cardiovascular disease. Current diabetes reports 2014;14(9):522. 


\section{Public Health England}
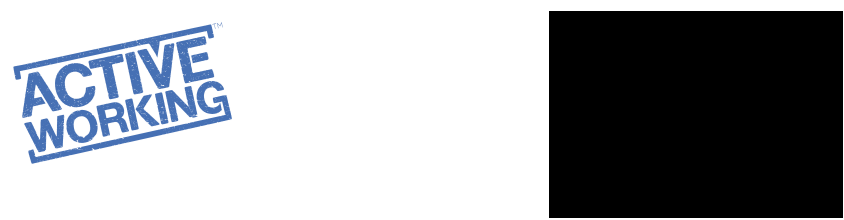

13. Thorp AA, Kingwell BA, Sethi P, et al. Alternating bouts of sitting and standing attenuate postprandial glucose responses. Medicine and science in sports and exercise 2014;46(11):2053-61.

14. Dunstan DW, Kingwell BA, Larsen R, et al. Breaking up prolonged sitting reduces postprandial glucose and insulin responses. Diabetes care 2012;35(5):976-83.

15. Thorp AA, Kingwell BA, Owen N, et al. Breaking up workplace sitting time with intermittent standing bouts improves fatigue and musculoskeletal discomfort in overweight/obese office workers. Occupational and environmental medicine 2014;71(11):765-71.

16. Hallal PC, Andersen LB, Bull FC, et al. Global physical activity levels: surveillance progress, pitfalls, and prospects. Lancet 2012;380(9838):247-57.

17. Troiano RP, Berrigan D, Dodd KW, et al. Physical activity in the United States measured by accelerometer. Medicine and science in sports and exercise 2008;40(1):181-8.

18. NHS. NHS Information Centre. Health survey for England-2008: physical activity and fitness. 2009. http://www.ic.nhs.uk/statistics-and-datacollections/health-and-lifestyles-related-surveys/health-survey-forengland/health-survey-for-england--2008-physical-activity-and-fitness., 2009.

19. HMGovernment. Moving More Living More; The Physical Activity Olympic and Paralympic Legacy for the Nation. London: The National Archives, 2014.

20. Townsend N BP, Wickramasinghe K, Scarborough P, Foster C, Raynor M. Physical Activity Statistics 2012. 2012b.

21. Henson J, Yates T, Biddle SJ, et al. Associations of objectively measured sedentary behaviour and physical activity with markers of cardiometabolic health. Diabetologia 2013;56(5):1012-20.

22. Kazi A, Duncan M, Clemes S, et al. A survey of sitting time among UK employees. Occupational medicine 2014;64(7):497-502.

23. Clemes SA, Patel R, Mahon C, et al. Sitting time and step counts in office workers. Occupational medicine 2014;64(3):188-92.

24. Thorp AA, Healy GN, Winkler E, et al. Prolonged sedentary time and physical activity in workplace and non-work contexts: a cross-sectional study of office, customer service and call centre employees. The international journal of behavioral nutrition and physical activity 2012;9:128.

25. Clemes SAH, J.; Munir, F.; Wilson, K.; Kerr, R.; Addley, K. . Descriptive epidemiology of domain-specific sitting in working adults: The Stormont Study. . Journal of Public Health 2015.

26. Ryan CG, Grant PM, Dall PM, et al. Sitting patterns at work: objective measurement of adherence to current recommendations. Ergonomics 2011;54(6):531-38.

27. Evans RE, Fawole HO, Sheriff SA, et al. Point-of-Choice Prompts to Reduce Sitting Time at Work A Randomized Trial. American journal of preventive medicine 2012;43(3):293-97. 


\section{Public Health \\ England}
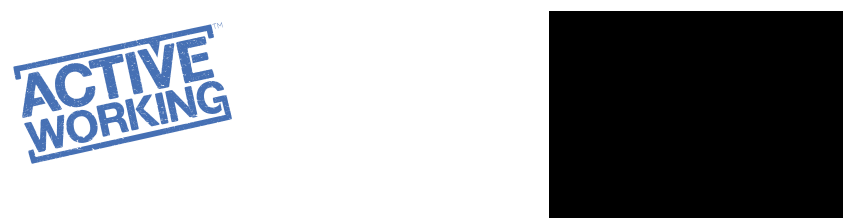

28. Brownson RC, Boehmer TK, Luke DA. Declining rates of physical activity in the United States: what are the contributors? Annual review of public health 2005;26:421-43.

29. Church TS, Thomas DM, Tudor-Locke C, et al. Trends over 5 decades in U.S. occupation-related physical activity and their associations with obesity. PloS one 2011;6(5):e19657.

30. Ng SW, Popkin BM. Time use and physical activity: a shift away from movement across the globe. Obesity reviews : an official journal of the International Association for the Study of Obesity 2012;13(8):659-80.

31. Fox KR, Hillsdon M. Physical activity and obesity. Obesity reviews : an official journal of the International Association for the Study of Obesity 2007;8 Suppl 1:115-21.

32. BHF. Sedentary behaviour; evidence briefing. Loughborough, UK, http://www.bhfactive.org.uk, 2012.

33. Stamatakis E, Ekelund U, Wareham NJ. Temporal trends in physical activity in England: the Health Survey for England 1991 to 2004. Preventive medicine 2007;45(6):416-23.

34. Proper KI, Singh AS, van Mechelen W, et al. Sedentary behaviors and health outcomes among adults: a systematic review of prospective studies. American journal of preventive medicine 2011;40(2):174-82.

35. Healy GN, Matthews CE, Dunstan DW, et al. Sedentary time and cardiometabolic biomarkers in US adults: NHANES 2003-06. European heart journal 2011;32(5):590-7.

36. Schmid D, Leitzmann MF. Television viewing and time spent sedentary in relation to cancer risk: a meta-analysis. Journal of the National Cancer Institute 2014;106(7).

37. Seguin R, Buchner DM, Liu J, et al. Sedentary behavior and mortality in older women: the Women's Health Initiative. American journal of preventive medicine 2014;46(2):122-35.

38. Wilmot EG, Edwardson CL, Achana FA, et al. Sedentary time in adults and the association with diabetes, cardiovascular disease and death: systematic review and meta-analysis. Diabetologia 2012;55(11):2895-905.

39. Grontved A, Hu FB. Television viewing and risk of type 2 diabetes, cardiovascular disease, and all-cause mortality: a meta-analysis. Jama 2011;305(23):2448-55.

40. Matthews CE, George SM, Moore SC, et al. Amount of time spent in sedentary behaviors and cause-specific mortality in US adults. The American journal of clinical nutrition 2012;95(2):437-45.

41. Hamer M, Stamatakis E, Mishra GD. Television- and screen-based activity and mental well-being in adults. American journal of preventive medicine 2010;38(4):375-80.

42. Teychenne M, Ball K, Salmon J. Physical activity, sedentary behavior and depression among disadvantaged women. Health education research 2010;25(4):632-44.

43. Bell JA, Kivimaki M, Batty GD, et al. Metabolically healthy obesity: what is the role of sedentary behaviour? Preventive medicine 2014;62:35-7. 


\section{Public Health \\ England}
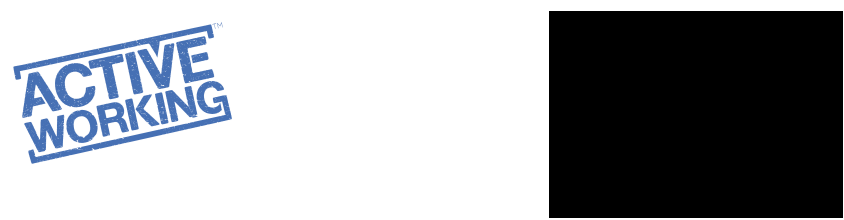

44. Hamer M, Stamatakis E. Screen-based sedentary behavior, physical activity, and muscle strength in the English longitudinal study of ageing. PloS one 2013;8(6):e66222.

45. Tikkanen 0 , Haakana P, Pesola AJ, et al. Muscle activity and inactivity periods during normal daily life. PloS one 2013;8(1):e52228.

46. Chau JY, Grunseit A, Midthjell K, et al. Sedentary behaviour and risk of mortality from all-causes and cardiometabolic diseases in adults: evidence from the HUNT3 population cohort. British journal of sports medicine 2013.

47. NICE P. PH 13; Promoting physical activity in the workplace. London: National Institute for Health Care and Excellence, 2008.

48. Morris JN, Heady JA, Raffle PA, et al. Coronary heart-disease and physical activity of work. Lancet 1953;265(6796):1111-20; concl.

49. Morris JN, Crawford MD. Coronary heart disease and physical activity of work; evidence of a national necropsy survey. British medical journal 1958;2(5111):1485-96.

50. ONS. Labour market projections 2006 - 2020. In: [UK] OoNS, ed. London, 2006.

51. Dogra S, Stathokostas L. Sedentary behaviour and physical activity are independent predictors of successful aging in middle-aged and older adults. J Aging Phys Activ 2012;20:S250-S51.

52. Chastin SFM, Mandrichenko O, Helbostadt JL, et al. Associations between objectively-measured sedentary behaviour and physical activity with bone mineral density in adults and older adults, the NHANES study. Bone 2014;64:254-62.

53. Gorman E, Ashe MC, Dunstan DW, et al. Does an 'activity-permissive' workplace change office workers' sitting and activity time? PloS one 2013;8(10):e76723.

54. Healy GN, Eakin EG, Lamontagne AD, et al. Reducing sitting time in office workers: short-term efficacy of a multicomponent intervention. Preventive medicine 2013;57(1):43-8.

55. Parry S, Straker L, Gilson ND, et al. Participatory workplace interventions can reduce sedentary time for office workers--a randomised controlled trial. PloS one 2013;8(11):e78957.

56. Chau JY, der Ploeg HP, van Uffelen JG, et al. Are workplace interventions to reduce sitting effective? A systematic review. Preventive medicine 2010;51(5):352-6.

57. Neuhaus M, Healy GN, Dunstan DW, et al. Workplace sitting and heightadjustable workstations: a randomized controlled trial. American journal of preventive medicine 2014;46(1):30-40.

58. Cooley D, Pedersen S. A pilot study of increasing nonpurposeful movement breaks at work as a means of reducing prolonged sitting. Journal of environmental and public health 2013;2013:128376.

59. Townsend N, Wickramasinghe, K, Bhatnagar, P, Smolina, K, Nichols, M, Leal, J, Luengo-Fernandez, R, Rayner, M. Coronary heart disease statistics 2012 edition. British Heart Foundation: London 2012. 


\section{期等 \\ Public Health \\ England}

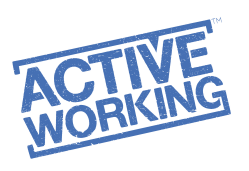

60. Comcare. STAND UP COMCARE-PROMOTING HEALTH BY TACKLING SITTING AS A RISK FACTOR FOR CHRONIC DISEASE. Canberra, 2013. 